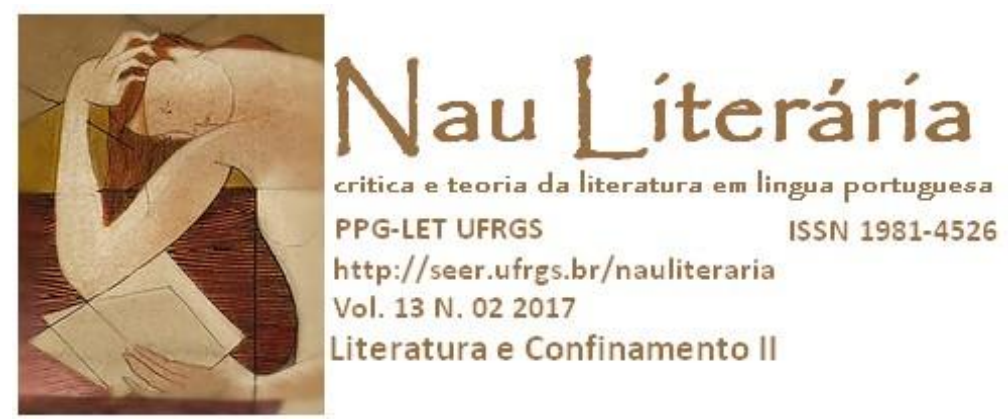

\title{
Caetés e a ordem do tempo
}

Maurício Gomes

Resumo: Este ensaio defende a centralidade da categoria de tempo em Caetés (1933), primeiro romance de Graciliano Ramos. O foco do texto é investigar as relações entre a monotonia de Palmeira dos Índios, e a subjetividade de João Valério e sua forma de narrar, articulando as esferas da forma e do conteúdo em torno de uma temporalidade supostamente dinâmica, mas efetivamente estática. Dessa investigação surge a hipótese de que Caetés se desenvolve enquanto romance de uma "não-história", ou melhor, figuração estética de uma conjuntura com formas sociais híbridas, a um só tempo arcaica e moderna.

Palavras-chave: Graciliano Ramos; Caetés; não-história.

Abstract: This essay defends the centrality of the category of time in Caetés (1933), the first novel by Graciliano Ramos. The focus of the text is investigating the relation between the monotony of Palmeira dos índios, and the subjectivity of João Valério and his narrative, articulating the spheres of form and content around a supposedly dynamic but effectively static temporality. From this research emerges the hypothesis that Caetés is developed as a novel of "non-history", or rather, as an aesthetic figuration of a conjuncture with hybrid social forms, at once archaic and modern.

Keywords: Graciliano Ramos; Caetés; non-histoty.

Ainda que muito variada em seus propósitos e abordagens teóricas, a fortuna crítica a respeito de Caetés se refere frequentemente, como maior ou menor ênfase, a um problema comum: a escassez de enredo no romance. Trata-se, em outras palavras, de chamar a atenção para a predominância de quatros cotidianos isolados sobre a articulação de ações no tempo, do que resultaria a impressão de uma temporalidade monótona ou circular, experenciada por personagens tipificadas:

Mas como o nosso escritor nos faz ver a monotonia com que vão pingando, gota a gota, as lentas horas provincianas! (GRIECO, 1978, p. 148).

Além disso, o processo do romance é de caráter fotográfico, com mais pitoresco do que dramaticidade; os personagens são tipos convencionais, que não se individualizam nem pelos seus atos nem pelos seus caracteres. (LINS, 1963, p. 160) 
Caetés é rebento dessa concepção de romance, minuciosa e algo estática (CANDIDO, 2012, p. 19).

Inexistindo em Caetés este "movimento" do herói, o romance resulta um mero acúmulo desorgânico de fatos superficiais, sem ligações íntimas entre si (COUTINHO, 1978, p. 81).

Fixada em seus aspectos físico, social e humano, a Palmeira dos índios que se oferece à nossa contemplação é a imagem do provincianismo mais desfrutável. É uma cidade onde nada acontece [...] (MOURÃO, 1971, p. 37)

Entretanto, para nós leitores, emerge o sentido circular do seu percurso: o protagonista se encontra, ao fim, na mesma situação do início. (GIMENEZ, 2013, p. 254) ${ }^{1}$.

Apesar da recorrência, é curioso notar que a categoria de tempo permanece, nessa tradição crítica, como dado lateral, sobrepujada por outras considerações frequentes (a pouca complexidade psicológica das personagens, a trajetória de João Valério ou ainda a volubilidade de sua narrativa). Invertendo essa equação, neste artigo procurarei não apenas demonstrar a centralidade da categoria de tempo em Caetés, mas sobretudo especificá-la enquanto problema dentro do romance, fazendo notar também sua irradiação na subjetividade de João Valério e, de modo mais geral, na forma de sua narrativa.

$* * *$

Comecemos por um resumo. João Valério, proprietário rural decaído, vem instalar-se em Palmeira dos Índios, onde, acionando seu capital de relações, emprega-se como guardalivros na casa comercial de Adrião Teixeira. Tão logo assume o cargo, passa a frequentar os serões na casa do patrão, apaixonando-se por sua esposa, Luísa. Esse quadro inicial, rememorado no terceiro capítulo de Caetés, é traçado apenas em linhas gerais, servindo como uma espécie de nó narrativo exterior às ações propriamente ditas do romance. Ainda assim, já oferece uma primeira "moldura temporal" à trajetória de Valério, diretamente ligada aos movimentos da história nacional: a passagem entre desagregação do regime senhorial e o início da República no Brasil. A personagem transita de senhor a funcionário do comércio, da ordem estamental à pretensa sociedade competitiva (nos limites provincianos e rudimentares de Palmeira dos Índios). Desse ponto de vista, mesmo em seu preâmbulo, a trajetória pessoal de Valério parece determinada pela passagem do tempo e pela suposta ruptura em relação ao "antigo regime" brasileiro.

Frequentando a casa de Adrião por cinco anos, ao fim de uma das tediosas reuniões noturnas entre o comerciante e seus aduladores, Valério aproxima-se de Luísa e dá-lhe um

\footnotetext{
${ }^{1}$ Grifos meus.
} 
beijo no pescoço, ao que a moça se mostra ofendida. Através dessa atitude transgressiva, ao menos para nós leitores, Valério funda-se enquanto narrador (o episódio do beijo inicia o romance). A partir daí, segue-se uma série de cogitações e temores: a demissão, a perda da posição conquistada, o fim dos serões com Luísa, o rompimento do cotidiano confortável, ainda que não ideal. À promessa de transformações, entretanto, sobrepõe-se a mais absoluta normalidade. Luísa nada fala e a vida cotidiana prossegue. Temos aqui uma recorrência ao longo de todo o romance: a promessa de "movimento" seguida da mais pura estagnação.

Mesmo assim, Valério decide precaver-se. Deixa de ir às reuniões na casa de Luísa, gastando seu tempo em conversas com os amigos da pensão onde vive e também com seu projeto literário, um romance histórico sobre os índios caetés (responsáveis pelo episódio da "deglutição" do Bispo Sardinha).

Esse último merece comentário à parte. Valério não tem pudor em afirmar sua ignorância sobre o assunto. Sua intenção não é produzir obra de valor estético ou científico, mas apenas consagrar-se localmente, aos olhos de Luísa, Adrião e das demais figuras de seu círculo social: "Não que esperasse embasbacar os povos do futuro. Oh! Não! As minhas ambições são modestas. Contentava-me um triunfo caseiro e transitório, que impressionasse Luísa, Marta Verejão, os Mendonça, Evaristo Barroca.” (RAMOS, 2013, p. 55)

Apesar do esforço, contudo, o texto não avança e é sob a forma de projeto gorado, de problema, que será referido ao longo do romance. Ainda assim, tanto sua natureza, quanto os motivos de seu fracasso são significativos. Dentre todos os gêneros literários possíveis, Valério escolhe o romance histórico, o que, obviamente, pressupõe a capacidade de "fazer história", isto é, de perceber e fixar racionalmente a diferença qualitativa entre o passado e o presente. Desse ponto de vista, o motivo que leva ao fracasso do projeto não poderia ser mais contraditório: segundo Valério, para além do pouco talento, falta-lhe a capacidade de elaborar um enredo (Cf. RAMOS, 2013, p. 28), de dispor as ações no tempo. Também lhe falta o distanciamento, já que as figuras do presente servem de molde aos personagens que pretende situar no passado, de modo que o cotidiano imediato invada a todo instante os cenários do romance histórico: "Matei alguns brancos, pendurei-os em galhos de árvores e esfolei-os, com a ajuda do Balbino. Depois entreguei-os às velhas, entre as quais meti a d. Engrácia, nua e medonha, toda listrada de preto, os seios bambos, os cabelos em desordem, suja e de pés de pato.” (RAMOS, 2013, p. 100)

Vale lembrar ainda a contradição do próprio episódio narrado: ao deglutirem o bispo português, os índios provocaram a ruptura momentânea da ordem, sobrepondo-se ao invasor 
branco, o que, por outro lado, levou à forte reação da coroa e ao genocídio dos caetés, afirmando assim o poder do regime colonial ${ }^{2}$. Em outras palavras, paira sobre o romance de Valério, enquanto projeto fracassado, a dificuldade de separar o passado do presente, além da contradição de um acontecimento histórico isolado, aparentando mudança, mas sem poder de transformação.

Assim como investe em sua obra inconclusa, Valério despende seu tempo, como já mencionado, entre conversas triviais, visitas à redação do jornal, para o qual contribui; e caminhadas. Luísa, ausente, some de seu horizonte. Ao menos até as reclamações de Adrião por conta da falta do guarda-livros nas palestras noturnas. Vendo-se pressionado, Valério volta aos serões e lá vê retornarem os desejos por Luísa. O movimento pendular desses desejos é útil para notarmos o quanto a imediatez é determinante para o personagem-narrador. Daí a impressão de certa volubilidade em suas resoluções e planos. O cotidiano impõe-se como força quase incontornável, diluindo a vontade individual de Valério segundo seus movimentos contingentes.

Estabelecida a reaproximação, os desejos de Valério seguirão diluídos conforme os estímulos imediatos. As expectativas com relação a Luísa ora aumentam, ora arrefecem, oscilando de acordo com as cenas domésticas em que se inserem: um olhar no serão, uma conversa no jardim, um gesto ciumento no jantar, etc. Em meio a isso, mais caminhadas sem rumo, mais conversas triviais, cenas domésticas e tentativas de fazer andar o romance histórico. Sobre as andanças de Valério, cabe destacar que são feitas em círculo ${ }^{3}$ e desprovidas de rumo, reforçando a contradição entre o movimento e a estagnação que atravessa o romance. Atendendo ao mesmo princípio, os longos debates travados em Caetés são uma sucessão de trivialidades desarticuladas, jamais chegando a qualquer conclusão - não raro há circularidade nos tópicos, voltando a conversa para seu ponto de partida.

Assim, entre um episódio e outro, pouca coisa acontece, apesar do movimento constante das personagens, sobretudo de Valério. O quadro só se altera por ocasião de uma viagem de Adrião à capital. Ficando a sós com Luísa, durante uma visita supostamente desinteressada, Valério a beija, firmando de vez a relação tão protelada. Os encontros furtivos

\footnotetext{
${ }^{2}$ Para uma revisão crítica do episódio, ver "Naufrágio e morte de D. Pedro Fernandes Sardinha, primeiro bispo do Brasil: sua revisão histórica", de Moacyr Soares Pereira (Revista do Instituto Histórico e Geográfico Brasileiro, Rio de Janeiro, n. 156, n. 387, p. 285-296, abr./jun. 1995).

${ }^{3}$ A trajetória circular das caminhadas de Valério pode ser averiguada quando acompanhamos seus itinerários através de um mapa do município de Palmeira dos Índios. Para uma versão atualizada desses itinerários, tendo em vista o atual nome das ruas, ver "Seguindo os passos de Graciliano Ramos em Caetés", de Jalon Nunes de Farias e Ana Paula Morais da Silva (Raído, Dourados, MS, v. 4, n. 7, p. 237-252, jan./jun. 2010).
} 
tornam-se frequentes, sendo logo comentados na cidade. De comentário esquivo, a relação passa a acusação direta, em meio a uma briga entre Valério e dr. Castro, promotor e figurão local. Também uma carta anônima é enviada a Adrião, denunciando o caso. Mais uma vez, criam-se expectativas de conflito, de ruptura. Diante das interrogações de Adrião, porém, Valério afirma inocência, ao que o patrão o libera sem maiores esclarecimentos.

Pouco tempo depois, contudo, Adrião atira contra o próprio peito, vindo a morrer após oito dias de sofrimento (em meio a que Valério reafirma sua inocência). Para nós leitores, o problema parece resolvido: eliminado seu principal obstáculo, Valério está livre para casar-se com Luísa. Mas isso não acontece. À morte do patrão, segue-se o afastamento do casal e, por fim, o término da relação. Valério torna-se sócio de Vitorino Teixeira na firma comercial de Adrião, cuja mandatária passa a ser Luísa. Ao fim do romance, como se tivesse andado em círculos, encontramos Valério frequentando serões na casa de Vitorino e nutrindo desejos por Josefa, filha do novo patrão. E a impressão de trajetória circular, de temporalidade estagnada, ganha força nas considerações finais do narrador, ao constatar, num misto de melancolia e cinismo, sua irmandade com os "primitivos" caetés.

A essa altura, é como se o romance arquitetado por Valério, enquanto projeto fracassado, encontrasse eco em sua própria trajetória. A mesma indistinção qualitativa do tempo, tensionando os polos da proximidade e da distância em relação ao passado, impede tanto a escrita do romance histórico, quanto a dinamização da vida em Palmeira dos Índios. Nesse caso, vemos o quão contraditória é a sociedade competitiva na qual Valério está inserido, na medida em que, privada dos dinamismos esperados na competição, constitui-se como uma ordem social estática, movimentada apenas em suas esferas mais superficiais. Ainda que o dinheiro circule na cidade, fica restrito aos investimentos previsíveis de uma elite envelhecida (da qual d. Engrácia é a típica representante) ${ }^{4}$. Da mesma forma, se existe o desejo de ascensão social, nutrido por Valério ao longo de todo o romance, não há meios racionalmente concebíveis para efetivá-lo (basta lembrar que a sociedade com Vitorino Teixeira vem por conta de um deus ex machina, a morte do patrão, e não do planejamento).

Imersa num contexto quase privado de dinamismos, a narrativa de Valério desenrolase sobre o agora persistente de Palmeira dos Índios, através da captação de seus quadros e

\footnotetext{
${ }^{4}$ A conformação contraditória entre o dinheiro e a estagnação é sugerida também na maneira como Valério guarda seus rendimentos: em meio às páginas do Eclesiastes ("Nada há de novo debaixo do sol”).
} 
movimentos imediatos ${ }^{5}$. Assim, ao registro das mudanças superficiais, sobrepõe-se a temporalidade circular, na tensão permanente entre a suposta progressão do tempo e a desconcertante duração do passado.

A duração do passado em Palmeira dos índios tem, sobre os personagens, um efeito direto, sua tipificação. Representados segundo suas manias, traquejos e características superficiais, os companheiros de Valério, desprovidos de história pregressa, repetem-se em seu cotidiano. Tudo ocorre como num tabuleiro de xadrez, metáfora recorrente no romance: ainda que mudem as situações, tanto o movimento das peças, quanto seus valores seguem sempre os mesmos. Daí a curiosidade despertada pela figura de Evaristo Barroca, arrivista que vai de pobretão a deputado do interior. O assombro causado pela ascensão do personagem, sobre o qual Valério não se cansa de cogitar, apenas demonstra o quão rara e surpreendente é a própria possibilidade de ascensão, de rompimento com o tipo estagnado no tempo.

Mas Valério também procura resistir à tipificação. Basta lembrar que é de sua perspectiva singular que acompanhamos a vida da cidade. Ao descrever as figuras que o cercam, objetivando-as por meio da escrita, coloca-se, ao menos num plano simbólico, acima delas. E mais do que isso, o personagem-narrador não está de todo satisfeito: quer ascender socialmente, deseja a esposa do patrão e sonha consagrar-se com a literatura. Figura a si mesmo como alguém fora de lugar.

Essa, contudo, é apenas uma parte do problema. Pois, apesar da pretensa resistência da singularidade individual de Valério, o vemos a todo instante sucumbir às demandas e aos valores de Palmeira dos Índios. Basta lembrar que a ascensão social pretendida ocorre nos limites da cidade, o desejo amoroso é pela esposa do patrão e o sucesso literário é o comentário elogioso dos colegas de pensão ou de Luísa. Valério quer afirmar-se para além da ordem cotidiana de Palmeira dos Índios, mas procura fazê-lo segundo os parâmetros de seu círculo social. Temos aí, portanto, outra contradição estrutural de Caetés, diretamente ligada à primeira já pontada: a tensão entre a singularidade pretendida por Valério e sua diluição no cotidiano estático de Palmeira dos Índios. Daí a fraqueza das resoluções e a facilidade com que planos de futuro sucumbem aos estímulos imediatos. No caso de Valério, toda afirmação

\footnotetext{
${ }^{5}$ A esse respeito, chama a atenção a plenitude de Palmeira dos Índios enquanto cenário fixo da narrativa. Quase nada para além da imediatez da cidade é citado ou descrito, seja no presente ou no passado. A própria história nacional, quando referida, aparece coberta pela fantasia, sempre misturada às mentiras de Nicolau Varejão.
} 
de si ou pretensão de devir culmina em seu oposto, a indeterminação do tipo e a repetição do mesmo.

Essa contradição tem efeito direto sobre a forma do romance. Podemos notá-lo naquilo que, conforme a crítica, parece ser o princípio de composição da narrativa de Valério, a oscilação entre as planos da objetividade e da subjetividade ${ }^{6}$.

Vejamos um exemplo. Em seu quarto de pensão, interrompendo uma de suas tentativas de escrita, Valério projeta seu futuro com Luísa:

\begin{abstract}
Veio-me um pensamento agradável. Talvez gostasse de mim. Era possível. Olhei-me n espelho. Tenho o nariz bem-feito, os olhos azuis, os dentes brancos, o cabelo louro vantagens. Que diabo! Se ela me preferisse ao marido, não fazia mau negócio. E quando o velhote morresse, que aquele trambolho não podia durar, eu amarrava-me a ela, passava a sócio da firma e engendrava filhos muito bonitos.

Embrenhei-me numa fantasia doida por aí além, de tal sorte que em poucos minutos Adrião se finou, padre Atanásio pôs a estola sobre a minha mão e a de Luísa, os meninos cresceram, gordos, vermelhos, dois machos e duas fêmeas. À meia-noite andávamos pelo Rio de Janeiro; os rapazes estavam na academia, tudo sabido, a outra com um fazendeiro - e nós íamos no dia seguinte visitá-las em São Paulo. (RAMOS, 2013, p. 29)
\end{abstract}

O ritmo do trecho é rápido. Tão logo Adrião se fina, Valério casa-se com Luísa, engendrando filhos que, de uma oração à outra, já aparecem crescidos, casados e estabelecidos como proprietários. A vida inteira em um parágrafo. E o mais importante, vida para além de Palmeira dos Índios, no Rio de Janeiro ou em São Paulo. O devaneio, porém, é abruptamente interrompido:

\begin{abstract}
Um cão uivava na rua; os galos entrevam a cantar. O dr. Liberato pigarreava; Isidoro Pinheiro roncava o sono dos justos; esmoreciam no corredor as pisadas sutis do Pascoal e um rumor, também sutil, na porta do quarto de d. Maria José.

Excelente criatura. Depois que enviuvou, não consta que haja conhecido outro homem. Aqui pela hospedaria passam dezenas deles. Nenhum lhe agrada. O italiano, robusto, sanguíneo e de bigodes, satisfaz-lhe plenamente as necessidades do corpo e da alma. Boa mulher. Deus a conserve por muitos anos. (RAMOS, 2013, p. 29)
\end{abstract}

Do projeto de vida, Valério passa aos cães e galos da cidade. Deles, para os ruídos da pensão e para a figura de d. Maria José. Com isso, dilui-se o devaneio na imediatez cotidiana, e o discurso passa da subjetividade ao plano objetivo, para em seguida voltar às impressões subjetivas a respeito da dona da pensão. Assim, por mais que Valério projete futuros e sustente impressões pessoais, há sempre o cotidiano imediato a puxá-lo de volta ao chão de Palmeira dos Índios, o que garante à narrativa a alternação constante de foco e a volubilidade entre os planos descritos.

\footnotetext{
${ }^{6}$ Para uma descrição detalhada desse procedimento formal, ver MOURÃO (1971).
} 
Vale notar ainda que a volubilidade se instala também no interior dos planos objetivo e subjetivo. Assim como vaga o pensamento do narrador ao sabor dos estímulos cotidianos, somam-se em seu discurso as descrições erráticas, o que, por sua vez, apenas reforça a subjetividade volúvel e dispersa de Valério. Durante um jantar na casa de Vitorino Teixeira, por exemplo, o narrador acompanha a conversa dos convidados, dividida entre a instrução pública, o problema da iluminação elétrica na cidade e uma receita de caruru apimentado:

- É claro, não há dúvida. Necessitamos luz, muita luz.

- Com miolo de pão? perguntou Clementina.

- Com miolo de pão, respondeu d. Josefa. Miolo de pão, goma-arábica e tinta. Também se faz com papel machucado na água.

- O senhor é o presidente da junta escolar? (RAMOS, 2013, p. 86)

A notação das conversas, no entanto, vem alternada, num imbricamento de considerações que aponta à dispersão de quem as observa. O quadro objetivo, nesse caso, não se constrói segundo os critérios de causa e efeito, mas conforme a reação de Valério aos estímulos que o cercam. Movimento semelhante ocorre no interior das cogitações e planos do narrador. Por exemplo, estando na casa de Luísa e recebendo convite do criado Zacarias para o jantar, Valério indigna-se: "Sim senhor! Mandar o preto convidar-me! Era, sem contestação, uma ofensa mortal. Pois não tornava a pisar ali. Fosse tudo para o diabo. [...] Que me importava o xadrez? Que me importava o piano?" (RAMOS, 2013, p. 97). Tão logo firma resolução de não voltar a ver Luísa, planeja novo casamento, desta vez com Marta Varejão: "Do piano resvalei para Marta Verejão e para os quinhentos contos de d. Engrácia. Marta Varejão, muito bem. [...] Pois casava com ela e havia de ser feliz, em Andaraí, na Tijuca ou em outro bairro dos que vi nos livros" (RAMOS, 2013, p. 97). Dos novos planos, o narrador retorna à indignação inicial, para logo em seguida afirmar suas qualidades: "O criado preto! "Diga a seu Valério que venha comer". Isto a mim, a mim que era...” (RAMOS, 2013, p. 97) A alternação de focos se mantém até o fim do capítulo, passando ainda pelo projeto de romance histórico e por novas considerações a respeito de Luísa.

A volubilidade, a ausência de direção fixa e de planejamento transformam-se, portanto, em princípio formal na narrativa de Valério, diretamente ligado à sua condição enquanto personagem, entre o tipo e o indivíduo, e, de modo mais geral, à temporalidade estática de Palmeira dos Índios, sua imersão na não-história ${ }^{7}$.

\footnotetext{
${ }^{7}$ Conforme Paulo Arantes (2000), em seu comentário a respeito de Hegel, a não-história caracteriza-se por uma temporalidade cíclica, na qual a mudança aparece esvaziada de força transformadora. Nas comunidades sem história, portanto, o devir é diluído nos movimentos da contingência, do que resulta o império da duração - ao
} 
Em vista do que foi dito, poderíamos afirmar, de maneira geral, que, em Caetés, se trata de um romance sobre a não-história de Palmeira dos Índios, ou melhor, sobre a desagregação individual em meio a uma temporalidade constituída enquanto "perpétua repetição do mesmo". No entanto, essa generalização não basta para descrever o romance de Graciliano. Há que se levar em conta ainda a especificidade do problema nos limites da incipiente República brasileira.

Graciliano não figura a imobilidade esperada no mundo senhorial, regido pelo estamento, mas sua continuidade desconcertante em meio à sociedade competitiva, pretensamente democrática, dinâmica e moderna. Daí ser a contradição a pedra de toque de seu romance: o tempo que passa apenas aparentemente, mas que é sempre engolido pela mesmice, o indivíduo que procura afirmar-se autônomo, ainda que preso numa ordem social imóvel, a narrativa que pretende enformar a realidade presente e passada, embora subjugada ao acaso da imediatez. Desse ponto de vista, a narrativa de Valério não deixa de ser um atestado de fracasso do indivíduo, da República e da sociedade competitiva em solo brasileiro. Ou ainda, um registro da coexistência entre formas modernas de sociabilidade e padrões arcaicos de dominação, do que resulta a diluição do moderno em meio às forças estacionárias do antigo ${ }^{8}$. Assim, mais do que um romance sobre a não-história de Palmeira dos Índios, Caetés configura-se também, podemos supor, como uma figuração do ritmo lento da mudança social no Brasil ${ }^{9}$, ao menos como este se deixa ver até a segunda metade dos anos 20.

\section{Referências}

contrário das comunidades com história, em que vigora a temporalidade cumulativa, garantida pela internalização do devir.

8 A respeito do ritmo da mudança social no Brasil, vale citar a célebre imagem oferecida por Florestan Fernandes: "Ele [o fluxo da mudança] não surgia insopitavelmente, como uma torrente volumosa e impetuosa, que abria seu caminho de modo inexorável. Mas uma espécie de afluente, que desaguava em um rio velho, sinuoso e lerdo. À medida que se formassem novos afluentes e, em particular, à medida que os homens drenassem o velho rio e o retificassem, é que a contribuição da massa de água adquirida iria revelar todo o seu potencial" (1979, p. 41).

${ }^{9}$ A compreensão de Palmeira dos Índios enquanto miniatura nacional é indicada pelo próprio Graciliano, em uma crônica publicada em 1921 (RAMOS, 2005, p. 83-86): "Palmeira é uma cidade essencialmente brasileira. Grande parte dos defeitos e das virtudes que no brasileiro se encontram, em geral, o palmeirense possui, em particular. Reproduz-se entre nós, em ponto pequeno, o que o país em ponto grande produz. [...] A pátria é um orangotango; nós somos um sagui. Diversidade em tamanho, inclinações idênticas." 
ARANTES, Paulo. Hegel: a ordem do tempo. São Paulo: Editora Huicitec/Editora Polis, 2000.

CANDIDO, Antônio. Ficção e confissão. Rio de Janeiro: Ouro Sobre Azul, 2012.

COUTINHO, Carlos Nelson. "Graciliano Ramos”. In: BRAYNER, Sônia. Graciliano Ramos. Coleção Fortuna Crítica 2. (Direção de Afrânio Coutinho). Rio de Janeiro: Civilização Brasileira, 1978.

FERNANDES, Florestan. Mudanças sociais no Brasil. São Paulo/Rio de Janeiro: Difel, 1979.

GIMENEZ, Erwin Torralbo. "Caetés: nossa gente é sem herói”. In: Caetés. Rio de Janeiro/São Paulo: Record, 2013.

GRIECO, Agripino. "Graciliano Ramos: Caetés". In: BRAYNER, Sônia. Graciliano Ramos. Coleção Fortuna Crítica 2. (Direção de Afrânio Coutinho). Rio de Janeiro: Civilização Brasileira, 1978.

LINS, Álvaro. "Valores e misérias das vidas secas". In: Os mortos de sobrecasaca. Rio de Janeiro: Civilização Brasileira, 1963.

MOURÃO, Rui. Estruturas: ensaio sobre o romance de Graciliano Ramos. Rio de Janeiro: Arquivo Editora e Distribuidora, 1971.

RAMOS. Graciliano. Caetés. Rio de Janeiro/São Paulo: Record, 2013.

Linhas Tortas. Rio de Janeiro/São Paulo: Record, 2005. 